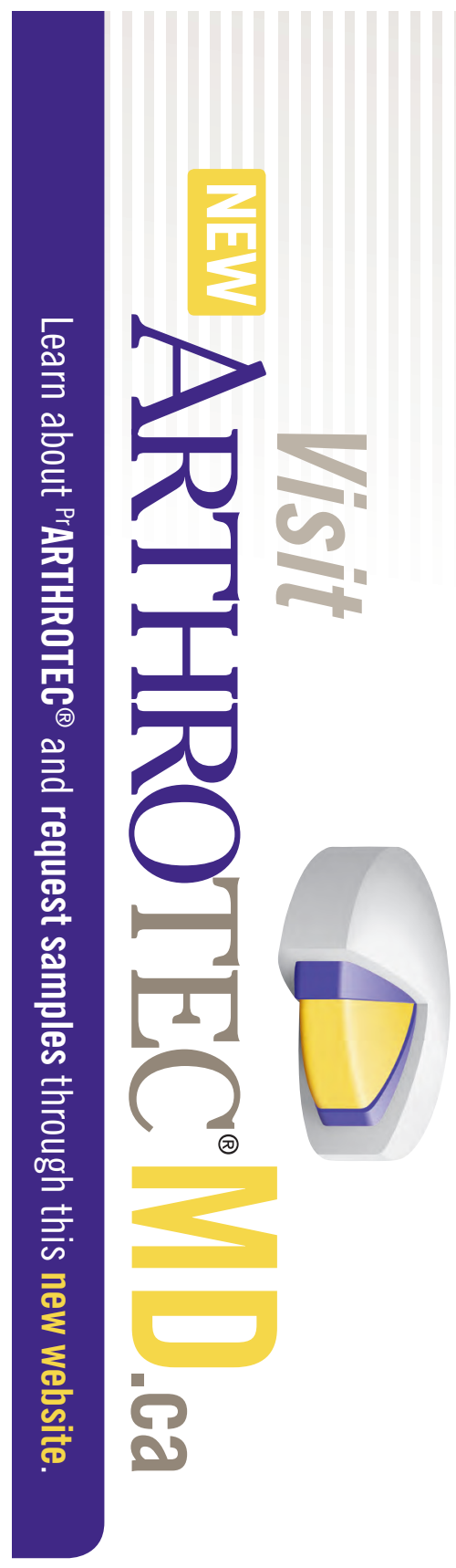

An NSAID with a mucosal protective agent, ${ }^{\text {PrARTHROTEC }}{ }^{\circledR}$ (50 \& $75 \mathrm{mg}$ diclofenac sodium and misoprostol tablets) has contraindications as wel as warnings and precautions of use.

Please consult the Prescribing Information which is available on the ARTHROTECMD.ca website, or the Product Monograph which is available upon request.

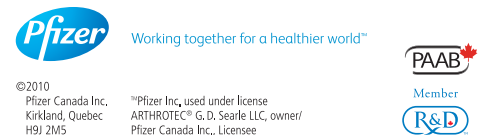

LETTERS

\section{Cardiovascular disease among South Asians}

Cardiovascular disease in our country has reached epidemic proportions, and we commend Chiu and colleagues for their thorough investigation into the role of ethnicity and risk factors. ${ }^{1}$

There is no question that South Asians have higher rates of diabetes than the general population and that poor diet and exercise are the major risk factors behind this trend. What was surprising from the study was that the rate of coronary artery disease was reported to be higher in the Caucasian subgroup than in the South Asians. We are unclear how to interpret this information in light of the growing evidence for disproportionately high rates of coronary artery disease among South Asians. ${ }^{2,3}$ We wonder whether the methods (i.e., self-reported measures) influenced the results of Chiu and colleagues' study.

Nevertheless, it is clear that we require more definitive measures for determining the rates of coronary artery disease in the South Asian population in Canada. We hope that Chiu and colleagues' article sets the precedent and generates further interest to encourage high-quality epidemiologic studies in Canada. Such work will be fundamental to policy decisions required to reduce the burden of cardiovascular disease in this country.

\section{Arun K. Garg MD}

University of British Columbia and Fraser Health

\section{Pamela Verma}

University of British Columbia,

Vancouver, BC

\section{REFERENCES}

1. Chiu M, Austin PC, Manuel DG, et al. Comparison of cardiovascular risk profiles among ethnic groups using population health surveys between 1996 and 2007. CMAJ 2010:182:E301-310.

2. Bhalodkar NC, Blum S, Rana T, et al. Comparison of levels of large and small high-density lipoprotein cholesterol in Asian Indian men compared with Caucasian men in the Framingham Offspring Study. Am J Cardiol 2004;94:1561-3.

3. Bainey KR, Jugdutt BI. Increased burden of coronary artery disease in South-Asians living in North America. Need for an aggressive management algorithm. Atherosclerosis 2009;204:1-10.
For the full letter, go to: www.cmaj.ca/cgi/eletters /182/8/E301\#552201

DOI: 10.1503/cmaj.110-2097

We thank Garg and Verma for their comments on our article. In our study, South Asians actually had a slightly, nonsignificantly higher overall selfreported prevalence of heart disease (5.2\%), compared with the Caucasian group $(5.1 \%)$. However, there appeared to be a gender interaction, whereby the difference between the two groups was greater among women than men.

We agree that self-reported data on prevalence warrant further study with more objective data sources, such as clinical registries or administrative databases. There may be important ethnic differences - such as age at presentation, types of heart disease (e.g., angina, myocardial infarction v. congestive heart failure) and survival after acute cardiac events as well as recall of previous events - that influence the overall prevalence of heart disease. We hope our article will be a stimulus for additional research so appropriate interventions can be undertaken to reduce disparities in the burden of cardiovascular disease and stroke in Canadians from all ethnic groups.

\section{Maria Chiu MSc \\ Jack V. Tu MD PhD}

Institute for Clinical Evaluative Sciences, University of Toronto, Toronto, Ont.

For the full letter, go to: www.cmaj.ca/cgi/eletters /182/8/E301\#589780

DOI: 10.1503/cmaj.110-2098

\section{Letters to the editor}

In submitting a letter, you automatically consent to have it appear online and/or in print. All letters accepted for print will be edited by CMAJ for space and style. Most references and multiple authors' names and full affiliations will appear online only. (The full version of any letter accepted for print will be posted at cmaj.ca.) 